\title{
Methodological problems in research on the diffusion of management practices
}

\author{
Problemas metodológicos en investigaciones sobre la difusión \\ de prácticas administrativas
}

\author{
Arturo Briseño ${ }^{1 *}$, Bryan W. Husted ${ }^{2}$ and Jorge M. Rocha ${ }^{2}$ \\ ${ }^{1}$ Universidad Autónoma de Tamaulipas, Mexico \\ ${ }^{2}$ Tecnológico de Monterrey, Mexico
}

Received 01 October 2016; Accepted 26 September 2017

Available online 5 November 2018

\begin{abstract}
Management research has benefited from the incorporation of social network theory, which helps explain the intrinsic social complexity in diffusion processes. However, this complexity requires statistical methods that better capture the relational nature of the data and changes occurring over time. Failure to do so could lead to erroneous conclusions for theory and practice. In this paper we highlight some of the methodological problems existing when analyzing social network data with traditional econometric methods. We concentrate on the diffusion of managerial practices literature, reviewing studies where network data has been used and identifying problems that might arise with selected econometric methods. We also present the Stochastic Actor Oriented Model (SAOM) as an alternative statistical method that possesses four advantages over traditional econometric models when using social network data.
\end{abstract}

JEL Codes: C01, C18, M10, M14

Keywords: Social networks; Management practices; Diffusion; Methodology; Influence.

*Corresponding author.

E-mail address: abriseno.dca@gmail.com (A. Briseño)

Peer Review under the responsibility of Universidad Nacional Autónoma de México.

http://dx.doi.org/10.22201/fca.24488410e.2018.1251

0186-1042/C 2019 Universidad Nacional Autónoma de México, Facultad de Contaduría y Administración. This is an open access article under the CC BY-NC-SA (https://creativecommons.org/licenses/by-nc-sa/4.0/) 


\section{Resumen}

La investigación administrativa se ha visto beneficiada por la incorporación de la teoría de redes sociales, la cual ayuda a explicar la complejidad social intrínseca en los procesos de difusión. Sin embargo, esta complejidad requiere métodos estadísticos que capturen adecuadamente la naturaleza relacional de los datos y los cambios que ocurren en el tiempo. No hacerlo puede llevar a conclusiones erróneas tanto teóricas como prácticas. Este artículo identifica algunos de los problemas metodológicos que existen cuando se analizan datos de redes sociales con métodos econométricos tradicionales. Nos concentramos en la literatura de difusión de prácticas administrativas, revisando estudios donde se han utilizado datos de red e identificando problemas que pueden surgir con los métodos seleccionados. Se presenta también el Método Estocástico Orientado al Actor (SAOM) como una opción de método estadístico que posee cuatro ventajas sobre los modelos estadísticos tradicionales al usar datos de redes sociales.

Códigos JEL: C01, C18, M10, M14

Palabras clave: Redes sociales; Prácticas administrativas; Difusión; Metodología; Influencia.

\section{Introduction}

Literature on the diffusion of managerial practices has made important advances over the past three decades using social network analysis as a theoretical or empirical framework (Backiel, Baesens, \& Claeskens; Davis \& Greve, 1997; Guler, Guillén, Muir, \& Macpherson, 2002; Shipilov, Greve, \& Rowley, 2010). Although these studies incorporate social network concepts and data, management scholars have generally applied standard econometric models. Unfortunately, social network data violates the assumptions of these models, reducing their explanatory power and overestimating the coefficients and their significance (Burk, Steglich, \& Snijder, 2007; Robins, Lewis, \& Wang, 2012). Failure to use techniques that are appropriate for social-network data can lead to a misinterpretation of how practices become widespread within a set of firms and an inability to capture the processes behind network change occurring in the process of diffusion.

The use of traditional econometric analysis to study longitudinal networks has been criticized for not being able to control for unobserved heterogeneity of social network data across time (Robins et al., 2012; Veenstra, Dijkstra, Steglich, \& Van Zalk, 2013). One of the major problems in using traditional econometric models for network data is related to the assumption that the random variables are independently and identically distributed (i.i.d.). Network researchers require relational data in which actors' responses are influenced by other actors and, in the case of a longitudinal studies, this influence needs to be collected over time (Huisman \& Snijders, 2003; Snijders, 2001). The traditional way of treating social network data has been to reduce actor or dyadic variables into vectors and use it with traditional longitudinal econometric models such as hazard rates or panel models (Burk, Steglich, \& Snijder, 2007).

Outside the management literature there have been attempts to understand how traditional approaches to longitudinal network data present an incomplete picture. For example, in sociology and medical studies, Veenstra et al., (2013) highlight the limitations of traditional longitudinal network studies when aiming to detect network behavior dynamics. However, the management literature has generally overlooked these methodological issues that could potentially alter our understanding of management phenomena. 
The methodological implications of this paper apply not only to the study of diffusion of managerial practices, but also to other areas of management research, such as entrepreneurship and inter-organizational alliances, which also have incorporated social network data and analyze them using traditional econometric methods. Consequently, the aim of this paper is to present how social network data has been used in the literature to explain the diffusion of managerial practices and highlight in which ways this approach could be problematic. Also, we will explain new advances in statistical methods that can deal with social network data over time, concentrating on the Stochastic Actor Oriented Model (SAOM), which considers the network inter-dependencies between changes in both network ties and actor behavior.

This paper is structured as follows. In the first section we expose the empirical approaches traditionally used to study the diffusion of managerial practices in social networks. In the second section, we explain the SAOM as an alternative statistical method to address social network data. Finally, we offer some concluding thoughts about the importance and relevance of this methodological approach.

\section{Social network data in the diffusion of management practices}

In isolation, the decision of an organization to adopt a managerial practice could be regarded as completely idiosyncratic. However, since organizations are immersed in a network of relationships, this is unlikely to occur. With this in mind, researchers have gradually introduced social network theory to explain organizational phenomena in the social sciences. Different areas in management have incorporated social networks, such as inter-organizational collaborations (Powell, White, Kogut \& Owen-Smith, 2005), entrepreneurship (Batjargal, 2010; Coviello 2006; Schutjens \& Stam, 2003), international expansion (Hatani \& McGaughey, 2012), and the global diffusion of managerial practices (Guler et al., 2002). These studies have handled social network data with traditional econometric models.

Social network theory helps explain how social interactions among connected actors in a network shape individual and organizational behavior (Wasserman \& Faust, 2009). According to this literature, it is the relationships among actors which determine individual behavior and provide a richer understanding of the process of social reality (Borgatti \& Foster, 2003; Granovetter, 1983). While social networks provide a richer platform to study many of the social phenomena in management, it represents a double-edged sword methodologically. Specifically, the social richness violates the assumption of independency needed in traditional econometric methods. The i.i.d. property assumes that the data is not auto-correlated and that each observation is independent from any other observation (Greene, 2012). However, social network data explicitly or implicitly involve interdependencies that cause strong correlations among observations. Despite this, social network concepts have been increasingly used to explain organizational phenomena (Borgatti \& Foster, 2003; Brass, Galaskiewicz, Greve, \& Tsi, 2004).

An example of how social network data has been used to study the diffusion of managerial practices is the work of Galaskiewicz and Burt (1991). Initially, in his work on corporate philanthropy, Galaskiewicz (1985) reported limited support for the idea that direct contact, i.e. cohesion between corporate philanthropic officers in large firms influenced the selection of prospective nonprofit organizations. However, by incorporating the concept of structural equivalence (the similarity of connections between actors), they found clearer explanations. These partial results found by Galaskiewicz (1985) occurred because direct contact was not 
the strongest network mechanism that generated contagion in comparison with structural equivalence, which concentrates on role similarities among philanthropic officers.

Early contributions to network analyses tended to be static in nature. More recently the literature has started to recognize the value of studying networks over time. Longitudinal analysis is of particular importance for diffusion studies since they allow researchers to understand the dynamics present in the evolution of social interactions. Examined longitudinally, social networks can provide a good setting for understanding in detail the diffusion process. For example, the critical mass concept, which describes the point after which further diffusion becomes self-sustaining (Rogers, 2003), can be studied not only in terms of speed, i.e. the number of individual actors that adopt in a given year, but also in terms of the network mechanisms that drive such adoptions.

However, social network data require appropriate statistical methods that can deal with complex social interactions at different points in time. To analyze how social networks concepts have been used to study the diffusion of managerial practices we build on the work of Veenstra et al., (2013) and identify four situations where using network data and traditional econometric analysis can be problematic: (a) statistical approach, (b) dyadic orientation, (c) incomplete networks, and (d) changes in ties and behavior. Table 1 presents a summary of the main studies identified in this paper that incorporate social networks to explain diffusion of managerial practices.

Table 1

Studies on the diffusion of managerial practices. a) Statistical Approach, b) Dyadic Orientation, c) Incomplete Networks, d) Changes in Ties \& Behavior

\begin{tabular}{|c|c|c|c|c|}
\hline & Authors & Mangerial Practice & Statistical Approach & Statistical Problems \\
\hline 1 & $\begin{array}{c}\text { Burkhard \& Brass } \\
(1990)\end{array}$ & Information systems & MANOVA & $\mathrm{a}, \mathrm{b}, \mathrm{c}, \& \mathrm{~d}$ \\
\hline 2 & $\begin{array}{c}\text { Davis \& Greve } \\
\text { (1997) }\end{array}$ & $\begin{array}{l}\text { New corporate governance } \\
\text { practices }\end{array}$ & Hazardrate model & $\mathrm{a}, \mathrm{c}, \& \mathrm{~d}$ \\
\hline 3 & $\begin{array}{c}\text { Galaskiewickz \& Burt } \\
\text { (1991) }\end{array}$ & Corporate donations & $\begin{array}{l}\text { Autocorrleation model/ } \\
\text { Maximum likelihood }\end{array}$ & $a, b, \& d$ \\
\hline 4 & Gibbons (2004) & Managerial innovations & Modeling/OLS & a \& d \\
\hline 5 & $\begin{array}{l}\text { Guler, Guillén, Muir \& } \\
\text { Macpherson (2002) }\end{array}$ & ISO 9000 & $\begin{array}{l}\text { Poisson regression / } \\
\text { Fixed effects }\end{array}$ & $a, b, \& d$ \\
\hline 6 & $\begin{array}{c}\text { Shipilov, Greve, \& } \\
\text { Rowley (2010) }\end{array}$ & Governance practices & Logit regression & $a, b, c, \& d$ \\
\hline 7 & $\begin{array}{l}\text { Westphal, Gulati, \& } \\
\text { Shortell (1997) }\end{array}$ & TQM adoption & $\begin{array}{l}\text { Probit regression/ } \\
\text { Hazard rate }\end{array}$ & $a, b, c, \& d$ \\
\hline 8 & $\begin{array}{c}\text { Young, Charns, \& } \\
\text { Shortell (2001) }\end{array}$ & TQM adoption & $\begin{array}{l}\text { Cox proportional } \\
\text { hazard-rate model }\end{array}$ & $\mathrm{a}, \mathrm{b}, \mathrm{c}, \& \mathrm{~d}$ \\
\hline
\end{tabular}

Source: prepared by the authors

Statistical Approach

Traditional econometric analysis generally focuses on understanding relationships among variables in a set of data (Greene, 2012). Each observation is considered to be independent from any other observation in the data set. While this assumption is less problematic in areas such as finance or economics, it is not the case for other social sciences, such as sociology and organization studies, where many observations are not isolated, but dependent and influenced by other actors (Wasserman \& Faust, 2009). The richness in network data comes from the fact that there is a dependency or influence in how an individual understand and perceives his or her environment. 
In the case of the diffusion of new practices, studies have tried consistently to understand how an individual adopter is influenced by other adopters or non-adopters. However, so far these attempts have been made with statistical methods that assume independency and reduce network data to a set of vectors, eliminating the richness involved in its natural relational form (e.g. Martin-Rios, 2014; Markóczy, Sun, Peng, \& Ren, 2013; Wossen, Berger, Mequaninte, \& Alamirew, 2013). Other disciplines such as sociology or anthropology use network data as a set of matrices thus allowing a more efficient exploitation of the data. In its matrix form, social network data represents all relations among actors. However, by transforming that matrix into a vector, it only captures a fraction of the information. For example, a matrix of interlocks, ties among firms that share two or more board members, contains all possible relationships from one firm to any other in the network, usually expressed with a " 1 " where the relationship exist and a " 0 " where it does not. Furthermore, a matrix of interlocks can hold more information if the matrix is directed, i.e. when the tie between two firms have a particular direction in terms of the communication flow. In both cases, transforming the matrix into a vector results in losing much of this rich information that can be used to explain practice diffusion. Table 1 summarizes studies that use network data to explain diffusion of managerial practices. The standard approach is to use econometric models, such as hazard-rate models or panel regressions.

For example, Shipilov et al., (2010) concentrate on the entire institutionalization process tracing the diffusion of corporate governance practices in an interlock network, i.e. firms connected via mutual board members. They argue that the institutionalization process occurs in different stages or waves. What determines the speed or shape of the institutionalization process is the institutional logics from the actors' network. An institutional logic is defined as a specialized cognitive and normative system that determines what is socially acceptable or not during a particular period of time (Lounsbury, 2001; Scott, 1987). Shipilov et al., (2010) argue that once the actors share the same logic, the adoption of similar practices will be more likely. Their main findings suggest that in the first wave of diffusion, organizations adopt practices via imitation, regardless of the prevalent institutional logic, while subsequent waves of diffusion will depend on the type of logic among the actors.

The network data in the Shipilov et al., (2010) study consist in relational matrices for each of the years from 1999-2005. These matrices represent the ties connecting listed firms. In order to construct a panel of data, the next step is to convert these matrices into binary vectors. This network data is then ready to be used with other non-network variables such as the market-to-book ratio and negative press coverage. By vectorising the network of interlocks, the authors lose explanatory power from the matrix form, especially for directed networks. A directed network is a relational matrix that can present asymmetries in the ties, i.e. can provide information about the degree of reciprocity in the relationships. For example, in the case of interlocks, a non-directed matrix can only express that two firms are connected, but not which company sends the director and which company receives the director on its board.

Another situation in which reducing the matrix into a vector may result in the loss of information is the case of the network properties. Frequently, structural variables, such as centrality, are included to explain influence in the diffusion process. For example, Burkhardt and Brass (1990) measure the effect that changes in technology have on the organizational structure and power with the introduction a new information system. They collected data from employees via questionnaires in four waves with three month intervals and used MANOVA and cross-lagged correlations to analyze the data. The network data consisted of the number of 
ties a particular employee has along with closeness centrality, the position in which a specific actor is situated in relation to others, to help explain influence in the adoption of the practice. Closeness, as a network measure, is traditionally arranged in a matrix $\mathrm{n} \times \mathrm{n}$ form in which each actor has a particular position in respect to another. However, in order to include this variable into traditional econometrics it has to be converted into a vector loosing much of the richness find in its matrix form.

\section{Dyadic Orientation}

Another limitation of treating social network data with traditional econometric models is the dyadic limitations. Since a relational matrix nxn expresses the connections among n number of actors, the possible combinations for an individual actor are not only those resulting from a dyadic level but also for the interactions among triadic connections (Borgatti \& Foster, 2003). Triads are a common focus of analysis for core social network literature, but impossible to analyze with traditional econometric models used in management research. One of the main variables that describes a triad is transitivity, i.e. the possibility that two actors, connected to a third common actor, form a connection (Ripley, Snijders, Boda, Vörös, \& Preciado, 2014; Wölfer \& Hewstone, 2017). This effect is commonly explained with the phrase "a friend of my friend is also my friend", conveying the idea of homophily, which implies influence from indirect peers (Lazarsfeld, P., Berelson, B., \& Gaudet, H. 1944).

Dyadic connections are common feature in diffusion studies on managerial practices. For example, Westphal, Gulati, \& Shortell, (1997) focus on the adoption of TQM practices among alliance partnerships, which represents a dyadic connection, and use institutional and social network theories to explain practice adoption. To construct the network, they consider each firm alliance in order to detect influence from those who have adopted. Statistically, they use a probit regression and a hazard-rate model to test their hypothesis. They found that as the number of ties increases for a non-adopter to other adopters, so too does the probability of contagion or adopting the same practice. However, since they consider only dyadic ties they miss the potential effects from transitivity in the creation, maintenance or dissolution of ties and how triadic connections influence non-adopters for TQM practices.

Another study that can reflect the importance of including triadic effects is the work of Galaskiewicz and Burt (1991). As previously explained, the authors constructed a network of corporate contribution officers to detect mimetic behavior in corporate donations. The network consisted of each officer's connections to their counterparts in other firms as well as those to local non-profit organizations. To test their hypothesis, they analyzed a panel data set using OLS and autocorrelation models. Although including structural equivalence proves to be helpful for detecting influence in their data, the exclusive dyadic approach might provide a limited view of how contribution officers influence each other without considering triadic influences. For example, the transitivity effect between two officers indirectly connected via a common third actor, whether a firm or a non-profit, might be relevant in determining whom a firm imitates for their corporate donations. Also, triadic effects are relevant especially for structural equivalence since indirect connections can change to direct over time.

\section{Incomplete Networks}

A common issue in social networks is establishing the boundaries of the network. Frequently, social network researchers have to take an executive decision to determine where the network 
begins and ends (Borgatti \& Foster, 2003; Monaghan, Lavelle, \& Gunnigle, 2017). However, once the decision is made, the whole network and the information that it provides should be taken into account in order to exploit the data appropriately. In the case of diffusion studies of managerial practices, many of the current longitudinal statistical approaches tend to limit the number of connections from one year to the next.

For example, Davis and Greve (1997) study how interlock directors and geographic proximity influences the diffusion of two new corporate governance practices, i.e. golden parachute and poison pill, among 442 large industrial corporations in the U.S. In general, their findings suggest that the influence of interlocking firms is contingent on the characteristics of the practice. Influence from direct contact (interlocked firms) occurs when practices are more observable and perceived to be more legitimate. In this case, similar industry and similar network positions influence the adoption of corporate governance practices. In other words, the existence of an interlock between two firms (direct contact), one that has adopted and the other that has not, increases the speed of adoption. However, when no interlock exists, geographic proximity predicts similar adoption. Interestingly, this suggests that visibility of other firm's adoption was sufficient to influence non-adopters, even when a direct contact did not exist.

To achieve these results, Davis and Greve (1997) use a hazard-rate model, which measure the risk of adoption over time. A particular characteristic of hazard-rate models is that once a firm has adopted, it "drops" the observation from further calculations of adoption since those firms are no longer at "risk" of adoption. This reduction eliminates important connections from year to year and impedes a complete analysis of network effects.

Incomplete networks can also arise from other sources such as actors leaving the network from year to year or missing data. For example, Burkhardt and Brass (1990) report that only 49 employees from a total of 81 in their sample were present all four waves of data collected. This reduction was a result of employees leaving the firm between waves. Since traditional econometric models cannot account for these actor dynamics, it creates an uneven number of actors for each year in the network, thus reducing explanatory power. Davis and Greve (1997) also report dropping missing data in order to achieve better estimates.

Finally, another source of incomplete data comes from the challenge that represents collecting social network data over time. Network data can be hard to obtain in both primary and secondary sources. For example, for primary data, researchers need to apply a questionnaire to actors in a defined network in T1 and then return in T2 to collect information from the same individuals and repeat these steps until Tn is achieved. Although this is a challenge for any longitudinal study, in network analysis the challenges increase due to the relational quality of the data. In both primary and secondary sources of information, researchers have to map the network at each point in time, including individual characteristics, in order to be able to trace changes in the relationships.

\section{Changes in Ties and Behavior}

One of the crucial elements for studies on the diffusion of managerial practices is to understand how actors, either adopters or non-adopters, influence each other's adoption. This means that researchers using social network data are looking for how a specific behavior, i.e. adopting a practice, is explained by the ties that a firm or employee has. On a single point in time, these ties are static and provide only a partial picture of what is happening in the network. Over time however, these ties can be created, maintained, or dissolved increasing the 
dynamism in the network (Ripley et al., 2014). This dynamism has been greatly overlooked by organizational and management researchers, especially since most of the current statistical tools do not allow testing these effects.

Ties and behavior are two processes strongly linked (Steglich, Snijders, \& Pearson, 2010). An actor can be influenced to change its behavior because of its pre-existing ties to others, but also because a specific behavior can create ties to other actors that behave in the same way. Current statistical approaches used for managerial adoption are not able to separate selection from influence creating potential over-estimations. For example, Guler et al., (2002) aim to understand how firms located in different countries influence each other's adoption. For this cross-national study, they examine ISO 9000 certification in 85 countries from 1993 to 1998. Methodologically, they consider a fixed effects model using a Poisson regression with negative binomial analysis. They find that states and large foreign multinationals are key actors responsible for coercive isomorphism, while trade relationships among firms create both coercive and normative isomorphism. Guler et al., (2002) construct the network considering the connections to those countries already adopting the ISO certification as well as the connections to those with a trading relationship. However, their statistical approach is not able to separate ties and behavioral changes which might also explain ISO adoption.

Another issue with traditional econometric analysis dealing with social network data is that it ignores the changes occurring between each wave of data. Even longitudinally, traditional econometric models treat each wave as a collection of individual, cross-sectional data, unable to model the changes between waves. The lack of modeling between observations is not uncommon even in traditional social network statistical analysis, where the changes in ties and behavior between observations are usually not modeled, creating an overestimation from unobserved changes (Veenstra et al., 2013).

In an attempt to model the diffusion of beneficial and ambiguous innovations, Gibbons (2004) analyzed the diffusion of an innovation through six prototypical inter-regional network structures via computational modeling. These network prototypes range from unconstrained to constrained and from decentralized to centralized. Her findings suggest that the degree of network centralization influences the diffusion of innovations. In particular, ambiguous innovations tend to diffuse better in decentralized networks, while those innovations with clearer benefits diffuse better in more centralized networks. To estimate the likelihood of the diffusion, she used logistic regression analysis and OLS. However, these statistical methods do not allow modeling the changes between observations.

\section{Stochastic actor oriented model for longitudinal networks}

As an emergent approach in social sciences, social network theory has evolved to become more commonly used in other disciplines such as organizational theory, marketing, or health studies (Rogers, 2003). Part of the evolution of social network theory has been influenced by the need to understand how individual actors and networks as a whole behave over time (Provan, Fish, \& Sydow, 2007). However, the most interesting area for longitudinal network analysis is the development of the statistical methods that can appropriately analyze the data. Traditionally, the methodology used in longitudinal network analysis consists of three steps: first, collecting longitudinal data from a defined network; second, converting it into individual level variables (e.g. centrality) or tie level variables (e.g. structural equivalence); and third, using these values in conventional econometric analysis (Burk, Steglich \& Snijder, 2007). 
However, as explained in the previous section, using traditional econometric techniques to study longitudinal network data present problems, not only for failing to capture the processes behind network dynamics, but also since they violate the i.i.d. assumption (Burk, Steglich, \& Snijder, 2007; Robins et al., 2012). The social network literature has highlighted the limitations of the statistical methods used to study longitudinal network data. In their study, Veenstra et al., (2013) explain four limitations often found in longitudinal network studies. First, peer characteristics generally are collected via the focal respondent, which includes the limited perception of that particular actor over time. Second, changes in behavior and relationships that occurred between observations are not modeled, resulting in an incomplete picture of network dynamics. Third, studies focus exclusively on dyadic relationships, ignoring the transitivity from dyadic to triadic effects. Finally, traditional longitudinal network studies fail to examine complete networks obtaining partial conclusions of network changes. As explained in the previous section, some of these limitations are also present in the diffusion of managerial practices.

One method for solving some of these problems and capturing the processes behind network change is the stochastic actor-oriented model (SAOM). First developed by Snijders in 1996, SAOM is used for analyzing the co-evolution of network structures and individual behavior (Robins et al., 2012). SAOM uses at least two observations in the form of a network relational matrix and a behavioral variable. This method interprets the data as "the cumulative result of an unobserved sequence of elementary changes, resulting from decisions taken by actors between observation moments" (Veenstra et al., 2013:402). In his model, Snijders identifies two major processes that are involved in studying changes in networks over time, namely selection and influence. Selection refers to the actors' decision to associate with other actors in the network, where the network structure shapes these decisions. Accordingly, changes in network structure over time are linked to the creation, maintenance, and dissolution of ties among actors. These changes involve a selection process in which actors in a network can decide whether to create a new link, maintain the existing link, or terminate a link. As a result, selection involves changes in the ties with similar behavior over time.

In contrast, influence refers to how the behavior of a particular actor is determined by its ties. Accordingly, changes in behavior of individual actors over time are linked to changes in peer behavior. In this case, the changes are presented in actors' behavior and not in its ties. Both network structure (selection) and individual behavior (influence) are crucial and interrelated processes for studying network dynamics (Burk, Steglich, \& Snijder 2007; Steglich et al., 2010) Veenstra et al., 2013). These two processes are interconnected since they produce similar outcomes over time, i.e. network change. As a result, the methods used for studying networks longitudinally, need to consider these interdependencies as part of the modeling (Veenstra et al., 20013).

Failing to consider both effects can produce misleading findings in explaining the causes of change in the network. The SAOM allows separating both effects in order to understand the real sources of network change over time (Robins et al., 2013; Veenstra et al., 2013). Although both effects are important in the SAOM, the influence effect represents a more natural fit to study diffusion.

The basic premise in the SAOM is that "each actor makes decisions that optimize his or her position in the network according to short term preferences and constraints as well as a residual unknown element" (Burk, Steglich, \& Snijder, 2007: 398). For this to occur, the model makes 
several assumptions (Huisman \& Snijders, 2003; Veenstra et al., 2013). First, network changes over time are assumed to happen in individual micro-steps. This means that overall or macro changes are the result of the accumulation of a series of micro and sequential changes. Second, at any single point in time, both the network and behavior data are sufficiently informative. Third, actors' decisions depend only on the present state of the network and not from previous configurations. Finally, it is assumed that actors have full knowledge of the present state of the network in taking their decisions. An additional advantage of the SAOM is that it provides an opportunity for hypothesis testing for longitudinal networks.

To provide an example of how SAOM works, we illustrate the diffusion of a social and environmental certification sponsored by the Centro Mexicano para la Filantropía (Cemefi). Empresa Socialmente Responsible (ESR) involves a voluntary, self-evaluation that firms submit to Cemefi, who assess the firm's social and environmental practices. The certification began in 2001 and has steadily defused among firms over the last 15 years. In the case of ESR, the behavioral variable in the co-evolution model is the adoption of the ESR certification. In terms of the network, we use board interlocks, which represent the network of firms through which diffusion occurs. In this example, there are 177 firms during the period of 2007-2011 forming an asymmetric matrix ${ }^{1}$ of firm relationships.

Table 2 displays the results for the co-evolution model of ESR adoption. The results are divided in two, network (selection) and behavior (influence) dynamics. The network dynamics, which measures the propensity for tie creation, maintenance, and dissolution offers results for two concepts, i.e. outdegree ${ }^{2}$ and reciprocity. With an estimate of -3.33 , the negative sign for outdegree indicates that there is a tendency of tie dissolution in the network overtime. This means that, over time, listed firms in the BMV eliminate board interlocks relationships. In terms of reciprocity, the estimate of 3.25 indicates that there is a tendency to reciprocate dyadic and triadic ties. A relationship among two or more actors is reciprocal if both have connections to and from each other. As a result, the reciprocity estimate means that firms in the BMV respond to interlocked firms by allocating board members.

Table 2

Co-evolution model for ESR certification adoption during 2007-2011

\begin{tabular}{lll}
\hline Co-evolution model & & \\
ESR Adoption 2007-2011 & & \\
\hline Network Dynamics & Estimate & St Err \\
Outdegree & $-3.33 * * *$ & -0.11 \\
Reciprocity & $3.25 * * *$ & -0.15 \\
Behavior Dynamics & & \\
ESR Adoption linear shape & $1.73 * * *$ & -0.21 \\
ESR Adoption indegree & 0.06 & -0.05 \\
ESR Adoption outdegree & 0.01 & 0.04 \\
\hline Overall maximum convergence ratio: & 0.31 & $* * * \mathrm{p}<0.005$ \\
\hline
\end{tabular}

Source: prepared by the authors

\footnotetext{
${ }^{1}$ An asymmetric matrix is created when relations between actor $i$ and actor $j$ are not the same. So for example, in a matrix representing friendship actor $i$ can consider actor $j$ a friend, but actor $j$ might not consider actor $i$ a friend, resulting in an asymetric relationship.

${ }^{2}$ In an asymetric matrix, directionality of ties is possible to calculate using indegree/outdegree. Outdegree ties are those that are formed by the focal actor $i$, i.e. the direction of the tie is from actor $i$ to actor $j$. Conversely, indegree ties are those that the focal actor receives from others in the network i.e. from actor $j$ to actor $i$.
} 
Although selection is in itself an interesting variable, for the purpose of adoption and diffusion of practices, it is the behavioral component that has particular importance. Since the co-evolution model considers both selection and influence as the main effects in the network, each variable works as a control for the other. This means that ties are formed, maintained, or eliminated considering each actor's behavior and each change in behavior is calculated considering the changes in the ties. As a result, influence from each actor in the network can take into account the effect of the evolution of the network.

Table 1 also presents results for the adoption of the ESR certification, the behavior in this example. The estimate of indegree and outdegree with 0.06 and 0.01 respectively, indicates the influence in the ESR adoption over time. In this example, however, there is no significant effect. This means that board interlocks do not influence the adoption of the ESR certification during the 2007-2011. However, the linear shape expresses a rise in the number of adopters between waves. In other words, CSR adoption is increasingly contagious within the network of board interlocks, however this contagiousness is not caused by the ties in the network. Direct contact, represented by the indegree and outdegree or number of interlocks that a firm is not significant.

Finally, model convergence is an important criterion in SAOM. The latest requirement is that maximum convergence ratio should be less than 0.25 . The convergence ratios ${ }^{3}$ in the models presented in Table 2 are the result of the re-iteration of the previous results in the model as recommended in the RSiena manual (Ripley et al., 2014). In this example, the initial estimate was around the 1.5 and was improved to the 0.31 . Although it is not below the 0.25 criterion, it can be considered adequate for this sample size.

Despite Snijder's (2001) advances in network dynamics and Greenan's (2014) extension for diffusion purposes, there are also limitations in the use of the SAOM. For example, at the writing of this paper, there are still no statistical tests in the SAOM that consider diffusion contagion without direct contact, e.g. structural equivalence. So far, the SAOM is built under the assumption that influence for adoption occurs only via direct connections in the network. Thus, other forms of contagion, such as structural equivalence, cannot be tested with these models.

\section{Discussion}

We focus on the stochastic actor based model (SAOM), which is a recent statistical method that possesses four advantages over traditional econometric models when using social network data. First, the SAOM can deal with longitudinal social network data in a matrix form, avoiding the loss of explanatory power when reducing social network information into vectors and can better deal with the problems related to the interdependencies inherent in relational data. Second, the SAOM can deal with the properties of more complex relationships, such as triadic transitivity, moving beyond the traditional dyadic approach that econometric models deal with. Third, the SAOM operates with the complete network, dealing with actors entering and leaving the network without dropping observations and losing explanatory power. Finally, it can also

\footnotetext{
${ }^{1}$ Convergence ratio in RSiena is a criterion that needs to be met in order to guarantee that the model performs adequately. Model convergence is an indicator that the data fit the model that is been tested. A model does not converge if the changes in the estimation increase from iteration to iteration. The overall maximum convergence ratio is the maximum convergence for linear combinations of the estimation statistics tconv. $\max <=.25$, while the tmax is the convergence of the set of statistics directly used in the estimation.
} 
control for selection and influence mechanisms, two important and related processes involved in longitudinal network studies.

Although the SAOM has been used in a few studies for selection and influence purposes, e.g. Light, Greenan, Rusby, Nies, \& Snijders, (2013), the diffusion literature has not yet incorporated the SAOM to study diffusion across time. Longitudinal network analysis presents a methodological challenge for researchers since it requires collecting data at two or more points in time. Although this is a challenge for any longitudinal study, in network analysis the challenges increase due to the relational quality of the data. Network data can be hard to obtain from either primary or secondary sources. In both cases, researchers have to map the network at each of the points in time with its individual characteristics to be able to trace changes in the network relationships.

Another reason why the SAOM is still underused is undoubtedly related to the novelty of the technique. Although the SAOM has been present in the literature since 2001, there was no mathematical method developed to address diffusion in the SAOM until very recently. In her paper, Greenan (2014) explains that dynamic networks are an ideal setting to study the diffusion process. She extends Snijders (2005) stochastic model by incorporating a proportional hazard model, the most novel method in the diffusion literature, allowing the possibility to study diffusion in a dynamic network and a heterogeneous population. The inability to incorporate these two features, i.e. longitudinal social network data and heterogeneous populations, has been a constant limitation in traditional diffusion studies. Greenan's model addresses these problems by suggesting that the network in which diffusion occurs changes over time and the population in which diffusion occurs is not homogeneous. By extending the SAOM for studying diffusion, Greenan's model can also make use of the distinction between selection and influence in the diffusion process.

In the case of influence, current econometric methods handle superficially a more complex reality, more complex than simply counting the number of connections to other firms and tracking the changes in the connections from one year to the next. The dynamics generated by the creation of new ties or the dissolution of others need to be controlled in order to determine how firms influence each other for practice adoption.

In addition to the simplification of social network data occurring in traditional econometric models, there are social network effects that are not currently addressed by econometric models such as triadic influences. Although the concept of the dyad represents an important attempt to move away from assumptions around individual actors not embedded in a social context, dyads cannot fully reflect the complexity of social interaction. Diffusion of practices based on dyadic relations will tend to overestimate a direct contact since it cannot control for third-party influences.

Given the problems with the use of traditional econometric methods in the analysis of social network data, current knowledge about the diffusion of managerial practices may be seriously compromised. The statistically significant results found in the papers presents in this paper may very well be insignificant using the SAOM since it overcomes many of the limitations of traditional econometric models. Future research should take into account appropriate statistical tests when dealing with social network data in order to decrease the risk of erroneous estimations.

The example from the previous section illustrates how a co-evolution model could offer more detailed and alternative results than the traditional econometric methods. Despite evidence in 
the literature on direct contact influencing practice adoption, the results using board interlocks and CSR practices offer no influence via direct contact. Since SAOM allows the researcher to control for tie changes in the network overtime, the effect of board interlocks influencing practice adoption is not present.

This finding, however, does not necessarily eliminate the use of non-network econometric methods. The conclusion that can be drawn from the example is that social network data is complex enough that it requires more sophisticated econometric models. Also, the more traditional econometric models might be the only possibility for the relational data available. For example, the restriction on the number of actors that SAOM might be able to incorporate could be a severe limitation on the use of this technique. Another difficulty is the more detailed information that SAOM requires for the relational data, especially in terms of directionality. This challenge is especially crucial in organizational studies where relationships like alliances or board interlocks are more difficult to determine in comparison to individual level studies where friendship and drug consumption are more straightforward.

The methodological issues explained in this paper might extend beyond the literature on the diffusion of managerial practices and be applicable to other organizational disciplines. For example, Batjargal (2010) studies entrepreneurs using social network concepts such as structural holes, but uses a traditional regression technique. The SAOM can be applied to study networks of entrepreneurs longitudinally in order to test the dynamics in tie changes and its effect over new ventures. Conversely, the Powell et al., (2005) study of inter-organizational collaborations can be reanalyzed with the SAOM to understand the network dynamics present in the data. Since this study focuses on the antecedents of partner selection for collaborations among biochemical firms, the SAOM can provide a better statistical method to test their hypothesis in relation to the formation, maintenance, and dissolution of ties. In these and other cases, the SAOM should provide a more appropriate way to analyze longitudinal network data and provide more robust results.

\section{Conclusion}

Management research has benefited from the incorporation of social network theory, which helps explain the intrinsic social complexity in diffusion processes. However, this complexity requires statistical methods that better capture the relational nature of the data and changes occurring over time. Failure to do so could lead to erroneous conclusions for theory and practice. In this paper we highlight some of the methodological problems existing when analyzing social network data with traditional econometric methods. We concentrate on the diffusion of managerial practices literature, reviewing studies where network data has been used and identifying problems that might arise with selected econometric methods.

\section{References}

Backiel, A., Baesens, B., \& Claeskens, G. (2016). "Predicting time-to-churn of prepaid mobile telephone customers using social network analysis". Journal of the Operational Research Society, 67(9), 1135-1145. https://doi. org/10.1057/jors.2016.8

Batjargal, B. (2010). "Network dynamics and new ventures in China: A longitudinal study". Entrepreneurship and Regional Development, 22(2), 139-153. https://doi.org/10.1080/08985620802628864 
Borgatti, S. P., \& Foster, P. C. (2003). "The network paradigm in organizational research: A review and typology". Journal of Management, 29(6), 991-1013. https://doi.org/10.1016/s0149-2063(03)00087-4

Brass, D. J., Galaskiewicz, J., Greve, H. R., \& Tsai, W. (2004). "Taking stock of networks and organizations: A multilevel perspective”. Academy of Management Journal, 47(6), 795-817. https://doi.org/10.5465/20159624

Burk, W. J., Steglich, C. E., \& Snijders, T. A. (2007). "Beyond dyadic interdependence: Actor-oriented models for co-evolving social networks and individual behaviors". International Journal of Behavioral Development, 31(4), 397-404. https://doi.org/10.1177/0165025407077762

Burkhardt, M. E., \& Brass, D. J. (1990). "Changing patterns or patterns of change: The effects of a change in technology on social network structure and power". Administrative Science Quarterly, 35(1), 104-127. https://doi. org/10.2307/2393552

Coviello, N. E. (2006). "The network dynamics of international new ventures". Journal of International Business Studies, 37(5), 713-731. https://doi.org/10.1057/palgrave.jibs.8400219

Davis, G. \& Greve, H.R. (1997). "Corporate elite networks and governance changes in the 80's". American Journal of Sociology, 103(1), 1-37. https://doi.org/10.1086/231170

Galaskiewicz, J. (1985). "Professional networks and the institutionalization of a single mind set". American Sociological Review, 50(5), 639-658. http://doi.org/10.2307/2095379.

Galaskiewicz, J. \& Burt, R.S. (1991). “Interorganization contagion in corporate philanthropy”. Administrative Science Quarterly, 36(1), 88-105. https://doi.org/10.2307/2393431

Gibbons, D. E. (2004). "Network structure and innovation ambiguity effects on diffusion in dynamic organizational fields". Academy of Management Journal, 47(6), 938-951. https://doi.org/10.2307/20159633

Granovetter, M. (1983). “The strength of weak ties: A network theory revisited”. Sociological theory, 1983 (1), $201-$ 233. https://doi.org/10.2307/202051

Greene, W. H. (2012). Econometric Analysis, (7th Ed.). New York: Pearson Education.

Greenan, C. C. (2014). "Diffusion of innovations in dynamic networks". Journal of the Royal Statistical Society: Series A (Statistics in Society). 178(1), 147-166, https://doi.org/10.1111/rssa.12054

Guler, I., Guillén, M. F., \& Macpherson, J. M. (2002). "Global competition, institutions, and the diffusion of organizational practices: The international spread of ISO 9000 quality certificates". Administrative Science Quarterly, 47(2), 207-232. https://doi.org/10.2307/3094804

Hatani, F., \& McGaughey, S. L. (2012). "Network cohesion in global expansion: An evolutionary view". Journal of World Business, 48(4), 455-465. https://doi.org/10.1016/j.jwb.2012.09.002

Huisman, M. \& Snijders T. (2003). "Statistical analysis of longitudinal network data with changing composition". Sociological Methods \& Research, 32(2), 253-287. https://doi.org/10.1177/0049124103256096

Lazarsfeld, P., Berelson, B., \& Gaudet, H. (1944). The people's choice: how the voter makes up his mind in a presidential campaign. New York : Columbia University Press.

Light, J. M., Greenan, C. C., Rusby, J. C., Nies, K. M., \& Snijders, T. A. (2013). "Onset to first alcohol use in early adolescence: A network diffusion model”. Journal of Research on Adolescence, 23(3), 487-499. https://doi. org/10.1111/jora.12064

Lounsbury, M. (2001). "Institutional sources of practice variation: Staffing college and university recycling programs". Administrative Science Quarterly, 46(1), 29-56. https://doi.org/10.2307/2667124

Martin-Rios, C. (2014). "Why do firms seek to share human resource management knowledge? The importance of inter-firm networks". Journal of Business Research, 67(2), 190-199. https://doi.org/10.1016/j.jbusres.2012.10.004

Markóczy, L., Li Sun, S., Peng, M. W., \& Ren, B. (2013). "Social network contingency, symbolic management, and boundary stretching". Strategic Management Journal, 34(11), 1367-1387. https://doi.org/10.1002/smj.2072 https://doi.org/10.1002/smj.2072

Monaghan, S., Lavelle, J., \& Gunnigle, P. (2017). "Mapping networks: Exploring the utility of social network analysis in management research and practice". Journal of Business Research, July 76, 136-144. https://doi.org/10.1016/j. jbusres.2017.03.020

Powell, W. W., White, D. R., Koput, K. W., \& Owen-Smith, J. (2005). "Network dynamics and field evolution: The growth of interorganizational collaboration in the life. American journal of Sociology, 110(4), 1132-1205. https:// doi.org/10.1086/421508. 
Provan, K. G., Fish, A. and Sydow J. (2007). "Inter-organizational networks at the network level: A review of the empirical literature on whole networks". Journal of Management, 33(3), 479-516. https://doi. org/10.1177/0149206307302554

Ripley, R. M., Snijders, T. A., Boda, Z., Vödös, A., \& Preciado, P. (2014). Manual for SIENA version 4.0 (version May 10, 2014). Oxford: University of Oxford, Department of Statistics; Nuffield College. Available from: http:// www.stats.ox.ac.uk/siena/

Robins, G., Lewis, J. M., \& Wang, P. (2012). "Statistical network analysis for analyzing policy networks". Policy Studies Journal, 40(3), 375-401. https://doi.org/10.1111/j.1541-0072.2012.00458.x

Rogers, E. M. 2003. Diffusion of innovations. (5th Ed.) New York: Free Press.

Shipilov, A. V., Greve, H. R., \& Rowley, T. J. (2010). "When do interlocks matter? Institutional logics and the diffusion of multiple corporate governance practices". Academy of Management Journal, 53(4), 846-864. https://doi. org/10.5465/amj.2010.52814614

Schutjens, V., \& Stam, E. (2003). "The evolution and nature of young firm networks: A longitudinal perspective". Small Business Economics, 21(2), 115-134. https://doi.org/10.1023/A:1025093611364

Scott, W. R. (1987). "The adolescence of institutional theory". Administrative Science Quarterly, 32(4), $493-511$. https://doi.org/10.2307/2392880

Snijders, T. A. (2001). The statistical evaluation of social network dynamics. Sociological methodology, 31(1), 361395. https://doi.org/10.1111/0081-1750.00099

Snijders, T. A. (2005). Models for longitudinal network data. In, P. J. Carrington, J. Scott, and S. Wasserman, (Coord.), Models and methods for social network analysis, (pp. 215-247). Cambridge University Press: New York.

Steglich, C., Snijders, T. A., \& Pearson, M. (2010). "Dynamic networks and behavior: Separating selection from influence”. Sociological Methodology, 40(1), 329-393. https://doi.org/10.1111/j.1467-9531.2010.01225.x

Veenstra, R., Dijkstra, J. K., Steglich, C., \& Van Zalk, M. H. (2013). "Network-behavior dynamics". Journal of Research on Adolescence, 23(3), 399-412. https://doi.org/10.1111/jora.12070

Wasserman S, \& Faust K. (2009). Social Network Analysis: Methods and Applications. Cambridge University Press: Cambridge.

Westphal, J. D., Gulati, R., \& Shortell, S. M. (1997). "Customization or conformity? an institutional and network perspective on the content and consequences of TQM adoption". Administrative Science Quarterly, 42(2). https:// doi.org/10.2307/2393924

Wölfer, R., \& Hewstone, M. (2017). "Beyond the dyadic perspective: 10 Reasons for using social network analysis in intergroup contact research". British Journal of Social Psychology, 56 (3),609-617. https://doi.org/10.1111/ bjso. 12195

Wossen, T., Berger, T., Mequaninte, T., \& Alamirew, B. (2013). "Social network effects on the adoption of sustainable natural resource management practices in Ethiopia". International Journal of Sustainable Development \& World Ecology, 20(6), 477-483. https://doi.org/10.1080/13504509.2013.856048 